\title{
Bridging Students' Soft Skills Gaps with MOOCs
}

\author{
Paola Corti, Federica Brambilla, Susanna Sancassani \\ METID - Politecnico di Milano, Italy
}

\begin{abstract}
Students in STEM (Science, Technology, Engineering and Mathematics) enter the labour market with recognized high level technical skills, but often need to enforce their soft skills in order to build effective professional relationships, according to companies view. Polimi Open Knowledge (POK), the MOOCs portal developed by Politecnico di Milano, starts bridging this gap with a series of MOOCs on soft skills, opened by Conflict Management and Change Management and growing with a new course on Working into Multidisciplinary Teams [4]. In these MOOCs an innovative role is played by the integration between role plays and clips taken from famous movies, in order to foster the student personal engagement through involving and enjoyable resources.
\end{abstract}

\section{Introduction}

Politecnico di Milano is one of the main Polytechnic University in Italy [4]. It offers degrees in Engineering, Architecture, Design. Polimi Open Knowledge - POK (www.pok.polimi.it) is the MOOCs platform designed by METID (the service of Politecnico di Milano, devoted to e-learning and e-collaboration http://www.metid.polimi.it) on the basis of Open edX [4] [5].

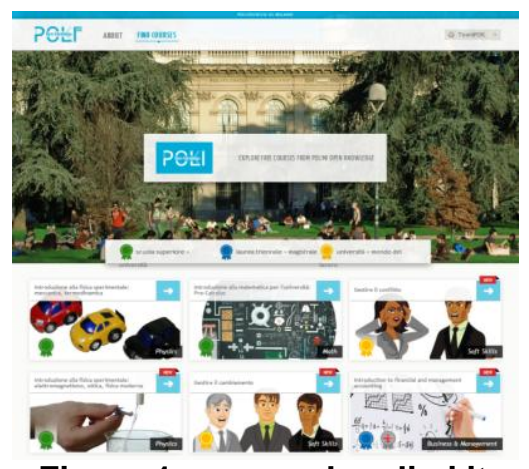

Figure 1. www.pok.polimi.it

The portal has been conceived for accompanying students in overtaking all the obstacles they can meet in the main passages of their career: from High school to University (in order to improve and consolidate their high school skills before starting courses at Polimi), from Bachelor of science to Master of science, (aligning their acquired skills to the ones of Polimi Master of Science, if they come from another educational path), from University to job, strengthening and enhancing their soft skills to smooth the step that takes them into the job scene. This paper is focused mainly on Soft Skills courses, developed in order to accompany students toward the job scene.

\section{Why not to take an Already Available Open Soft Skills Course?}

The online education scenario offers multiple open courses focused on all kind of soft skills: why not to suggest them to students? The problem is that creating MOOCs to bridge the specific gaps of STEM students requires to listen carefully to students specific needs, while potential other users don't have to face that particular passage from an identity of "student" to the identity of "worker". Companies' courses on soft skills, on the contrary, usually ask to "workers" to get back to "student's perspective" for a while, and study/experiment new skills in their everyday environment at work. POK courses on soft skills, on the contrary, focus on the need of students to come in touch with situations, problems and attitudes they may not have experimented yet. In July 2013 Polimi collected 130 answers to a survey sent to companies, in order to have their direct vision: while they all recognize a high level preparation in all technical fields, new employees coming from technical universities seem to lack of soft skills, conflict and change management on top [4].

Polimi chose to make these courses available in an open environment, addressing them not only to the 38.000 students of the university itself, but also to students from all other universities, in order to give the chance to raise as much as possible the background level of new-comers to the working scenario. Sharing knowledge, in fact, is one of the main objectives of this strategy [4].

Since these skills are strongly connected with cultural issues, we chose to design these first courses in Italian language, but it was just a first step. In fact, during 2015 one new soft skill course will be available, dealing with Working into Multidisciplinary Teams, and it is being developed directly in English. At the same time, POK will offer the chance to subscribe an English version of both Change Management and Conflict Management, being the accesses to the platform coming from all over the world (see Conclusions). 


\section{How Have These Courses been Designed?}

A content expert was involved in the design of each course, with an instructional designer on the side; this second professional was not only expert in didactical technologies but also in the specific content: this specific strategy was aimed in making the process sustainable, because otherwise the presence of the content expert would have been needed during the whole implementation of the courses.

The instructional designer, thus, was focused in matching the main content needs with the adopted didactical approach and the platform boundaries that has to be taken into consideration. The solution found for each stimulus, according to participants' feedbacks, seems to be pretty satisfactory at present time (see Conclusions).

\subsection{Structure of a Course and Didactical Approach}

Each course's contents are divided into weeks and modules, according to edX main framework; in other sections students can find multiple insights, in order to go deeper into their own experiences at different levels, and to recognise first of all if they've already acquired a "taste" of the skills related to the course in their personal life. Thus students are accompanied in bringing these skills to a conscious level and in using their experience consistently with different situations and issues taken from everyday working life. The choice of this approach is aimed at giving the greatest importance to personal attitudes to learning, including time schedule and interest into the insights.

In perspective POK team is going to increase the interaction between participants in the platform environment; at the moment it is limited to personal initiatives in reserved rooms, but with the new course under construction new room will be given to peer to peer activities.

The use of role plays, comics and movie clips, which are a consistent part of the courses, are quite new in the MOOCs scenario: METID strongly believes that direct involvement and pleasant contents can lead to better results in learning [5]. While movie clips offer the chance to analyse part of fiction stories according to the course's objectives, role plays push the user to play with different reactions (also negative ones) in order to learn from consequences, but remaining in a protected environment, which is typical of a learning path.

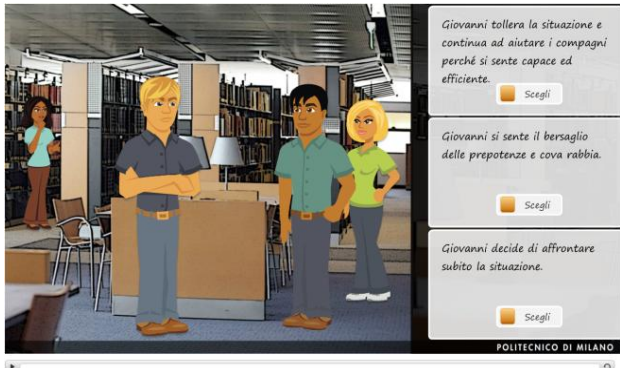

Figure 2. Example of Role Play

The courses include also some comics which were chosen by the instructional designer in order to make the theory parts lighter, and to capture the attention of the students on some important keyconcepts in order to help memorizing them.

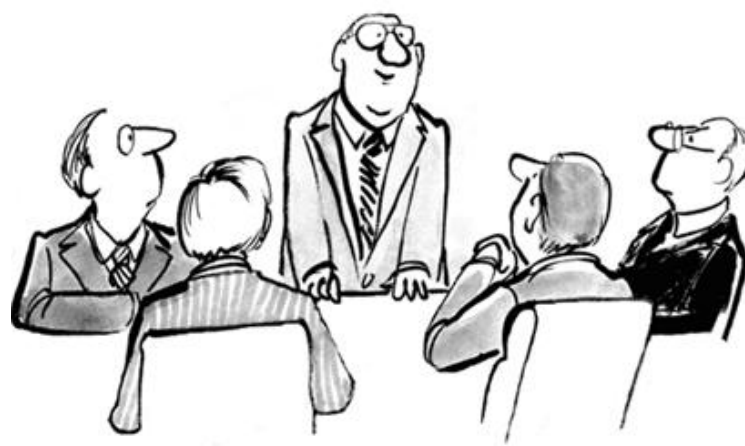

"What if, and I know this sounds kooky, we communicated with the employees."

Figure 3. Example of Comic

In the first two courses METID designed only small social activities for sustainability reasons, since it was the beginning of the experimentation and the Athenaeums internal request was to produce modules for individual study, as stated in the first part of this paper [5]. In the new course on Working into Multidisciplinary Teams POK team is going to increase the interaction in the platform, according to the willing of the institution and the available resources; in the new MOOC, in fact, peer to peer interaction will be part of some of the training activities and won't be limited to personal initiatives in reserved rooms.

A quiz closes each module: students who complete and pass the course with a total score higher or equal to $60 \%$ of the total receive a Certificate.

\subsection{Students' Direct Involvement in the Design Process}

Students have been involved since the very beginning, in order to design both structure and graphics taking into account their comments. METID organized focus groups in different levels of 
content's development, in order to verify the perception, the satisfaction and the impression about usefulness, clarity, immediateness, and pleasantness of the courses themselves [5]. All comments have been taken into account and, when possible, implemented to improve quality and effectiveness of courses.

Thanks to students wishes and suggestions, furthermore, the course on Change Management has been integrated with interviews to HR directors, multinational companies' partners and to former POLIMI students, in order to give a direct insight into particularly interesting perspectives: the one of decision makers who select and hire new people, the one of people who run part of the company at a higher level and the precise role of change management skills in the scenario of everyday working life, and the perspective of new-comers into the working class who are directly experiencing the same change many of the user are going to experience soon.

\section{One Step Further}

As previously mentioned, a new soft skill course is under development at the moment. It will focus on working in multi-disciplinary teams, and it will be the beginning of a new step in the evolution of POK: developed directly in English, it will include some peer to peer activities in order to make participants experiment different interactions, reflect on the interpersonal dynamics that will happen, and feel more responsible about the fulfilment of objectives with other students. It will be the chance for the staff involved to deepen their knowledge and experience processes which are new in the scenario of Polimi and which could open new ways of balancing teachers and students efforts in the courses themselves [4]. POK will thus continue to evolve and new gaps will be bridged also on the developers side.

\section{Conclusions}

POK portal was launched in June 2014 and at the beginning of December 2014 counts more than 63.400 sessions and 6.400 users, coming from 131 different Countries notwithstanding the existence of only one English course in an area which is not object of this paper (Financial Management). The first edition of Conflict Management closed on the $3^{\text {rd }}$ of November 2014; 429 students subscribed the course and 110 completed it, half of which succeeded in obtaining the certificate (the limit was set on the $60 \%$ rate of the total evaluation exercises); the first edition of Change Management is still ongoing; even if we never took action in spreading news about Soft Skills courses, the first two courses count around 800 users.
Questionnaires addressed to students are sent as soon as the first edition of each course comes to an end. In the questionnaire students are invited to give a feedback about the didactical effectiveness of the course they finished, but also to tell whether the formats used to propose contents are in their perception adequate to the aims of the course itself; they give hints also on their perception about the consistency between the course and their upcoming professional development; the aim of these questions is to collect as much information as possible from different users perspectives and make the design of next courses as much adherent to the real users' needs as possible, maintaining the flexibility which helps each of them in studying at his/her own pace.

Starting from the analysis of results coming from the first edition we are going to organize face to face meetings with other students, in order to disseminate results, invite new participants and integrate these courses with face to face activities, as soon as the university is ready.

\section{References}

[1] J. Huizinga, Homo ludens Einaudi, Torino 2002

[2] J. Juul, "The Game, the Player, the World: Looking for a Heart of Gameness". In Level Up: Digital Games Research Conference Proceedings, Marinka Copier and Joost Raessens, 30-45. Utrecht: Utrecht University, 2003. http://www.jesperjuul.net/text/gameplayerworld/.

[3] S. Sancassani, P. Corti, F. Brambilla, "From MOOCs to knowledge sharing", in Proceeding of: EADTU Conference- "Transition to open and on-line education in European universities", Paris 24-25 October 2013.

[4]Polimi Open Knowledge portal. http://www.pok.polimi.it

[5] METID Service - Politecnico di Milano. http://www.metid.polimi.it 